\title{
The Unaccepted Challenge: Faculty Development For Women
}

\section{Michele Fisher*}

There is a group that has too long been neglected by a movement that claims an especially broad and humanistic vision for higher education. The movement is of cource faculty development, the neglected group women faculty and graduate students. To replace neglect with effective action, faculty developers must begin to share strategies for first understanding, then changing the situation of women at all ranks and levels of academia. ${ }^{1}$ This paper presents one such strategy, together with a series of practical programs that developers can initiate.

Before I go on to discuss this strategy and various programs, I want to anticipate the sentiment that the responsibility for women's situation in academia properly belongs elsewhere on and off campus-in an affirmative action office, a women's center, a committee on the status of women, the provost's office, caucuses or subcommittees of professional organizations, state or federal legislatures, even the courts. Certainly I am not arguing that the faculty development effort should usurp these other agencies or expect to succeed alone where they-after years-have achieved little. Rather, it is increas-

\footnotetext{
*An earlier version of this paper appeared as "Faculty Development: Where Have All the Women Gone?" in Contributed Papers of the Seventh International Conference on Improving University Teaching, Tokyo, Japan, July 15-18, 1981, pp. 283-91. My sincere thanks to James Milojkvic and Callie Elliston for their helpful comments on earlier drafts; to Winifred Anderson for extended discussions on the topic; and to participants in a workshop on this subject at the 1981 POD annual convention in Cincinnati for their encouraging responses.
} 
ingly obvious that the full participation of women in academia requires fundamental changes in the basic organization and values of colleges and universities: to more opportunities for fully legitimized part-time employment; to more frequent hiring of an institution's own Ph.D. graduates; to more support for the reconciliation of competing personal and professional obligations; to a reconsideration of what constitutes legitimate areas and lines of scholarly inquiry. Since recent court cases indicate that such changes have little chance of being imposed from the outside, ${ }^{2}$ the driving force for reform clearly needs to originate from those already on campus. Among these, the local faculty developer-with an understanding of and influence over the instructional and organizational development of the institution-is uniquely equipped. Unfortunately, this expertise has yet to be fully mobilized for the nurturance and professional advancement of women academicians.

Once mobilized, there will be a very practical bonus to faculty development as a result of its involvement with women. It will gain new energy by reaching out to a group that, like it, feels the need for new values and approaches in the academy. Women, after all, have long been associated with the teaching rather than the research function of higher education. ${ }^{3}$ Partly this seems a result of their clustering in the ranks of part-time instructors and junior faculty, but certain surveys indicate that women academics simply value their teaching roles more than their male counterparts do. ${ }^{4}$ Women who have taught in Women's Studies or worked in women's groups are even more likely to have had to rethink the usual teaching methods and traditional curriculum. Many of them have described both the difficulty of establishing the legitimacy of their nontraditional courses and the exhilaration of teaching materials that require a different relationship with their students. ${ }^{5}$ When a year-long course on Western Culture was recently reinstated at Stanford, some of the most significant criticisms of its heavily traditional content and classroom organizations came from women faculty members experienced in feminist research.

But even if faculty developers decide to lend effective support to the efforts of women faculty and graduate students, how do they begin? This is where developers must begin sharing ideas and information. I offer one possible strategy. 


\section{First Steps}

Since most college campuses today have some type of women's groups, a faculty developer is well advised to begin any programs for women only after careful review of existing groups' materials and concerns. Women faculty of graduate students who have been prominent in Women's Studies programs or committees on the status of women are also natural contacts. Discussions with them can help determine how women on any particular campus perceive their situation and whether they have identified unmet needs. They may also offer insights into the administrative attitude toward women and the political climate a developer can anticipate in entering this ground. They are an excellent source of information on helpful background reading. Consultation with women known to be indifferent or hostile toward a feminist analysis of their situation is also necessary since they too are potential constituents but may only attracted to programs if no obvious ideological tone is attached.

With the groundwork thus laid, a developer may still be advised to try his or her first programs in co-sponsorship with an existing women's group of an informal coalition of women. This will make it less likely that territorial issues will arise or complicate future efforts. Through such collaboration a developer may also discover that a consensual or highly egalitarian style of program is preferred and adapt offerings accordingly.

If all this suggests that there are possible pitfalls to working with women, there are. The feminists among them are deeply concerned with issues of authority and power on our society and take these matters seriously on whatever level they find them, including choosing speakers for a program or whether a speaker is even appropriate. They will be especially concerned that programs for women neither reinforce stereotypes, nor patronize. The consolation, as I have experienced it, is that activists on women's issues place a particular value on recognizing people's efforts; they know the importance of "strokes." A developer will find the warmth and supportiveness of a women's community a welcome antidote to the variety of demands that burn out faculty developers just as much as other "helpers." 
A developer will want to continue to use this women's network in deciding what further programs or services his or her office should offer to the campus. To open up the options, I suggest below some steps that could be adapted to most institutions.

\section{Programs For Graduate Women}

Although women are entering doctoral programs in ever greater numbers, even in the overwhelmingly male-dominated fields of engineering and physical sciences, women doctorates continue to lag behind their male peers in the ranks and salaries that they achieve in academe, particularly at elite colleges or research universities. This situation persists in spite of considerable pressure on post-secondary institutions to use affirmative action hiring criteria. ${ }^{6}$ Researchers have identified causes ranging from an extreme on one side of discrimination by men to an extreme on the other of a fear of success among women. ${ }^{7}$ While faculty developers may not feel competent to treat either of these phenomena, they should offer other types of assistance:

(1) Forums - whether a panel, a workshop or a brochure through which experienced or recent faculty women can share their own strategies for having "made" it with those who are still struggling. It is particularly useful if these women talk about how they dealt with such problems as: reconciling their career goals with those of their husband or significant other; finding support for research in a nontraditional are a like Women's Studies: handling sexist behavior among peers or from a mentor; establishing the seriousness of one's career commitment in spite of children or moves with a husband; developing confidence that success is possible in spite of a lack of obvious role models.

Commentators might also be counselors or sensitive male faculty members or career specialists. There are advantages, however, to using only women faculty, at least on certain occasions. Graduate women are often eager to talk to women who have made it but hold back because of the mentoring or service demands already placed on these faculty. A panel not only gives the graduate women an opportunity to ask their questions but allows the faculty women to mentor in a large-scale, time-effective manner. At Stanford, the faculty who 
participated in such a forum remarked that they welcomed such opportunities to provide help to others in a way that did not sacrifice an undue amount of their own much needed research time.

(2) Forums that provide an inside view of the hiring process for assistant professors, laying stress on the informal mechanisms that operate in the selection of candidates. Such workshops should open to both men and women graduate students but are more crucial to women, who often still fall outside the information and patronage system known as the "old boys' network." Both male and female students should also be briefed on what affirmative action means in actual practice - to allay misconceptions or fear that it results in employment of candidates with poor credentials but the right sex or race.

(3) Programs sharing what little is known about the career patterns of academic women. Graduate women should be aware that their careers might not exactly duplicate those of their male peers and that pressure from them can eventually influence universities to accommodate the differences. ${ }^{8}$ Some institutions already give one-year extensions, for example, to assistant professors who bear a child during the years they are going for tenure.

(4) Assertiveness training workshops. Again, these can be offered to both men and women students - as they are at the University of Texas at Austin ${ }^{9}$-but women especially benefit from strategies to determine and defend their just rights.

(5) Research tracking your own institution's graduate women and their placement record. If research reveals that women are suffering significantly higher unemployment rates or ending up in less desirable positions, then the causes should be sought and publicized to the rest of the university, including relevant deans. There may be a local agency - such as the Center for Women Scholars in San Franciscothat is carrying on similar research and might suggest remedies.

(6) Cooperation with other groups on campus that may already be working with graduate women. Since women Ph.D.s seem to fare less will than male peers in industry as well as academia, faculty developers should cooperate with on-campus career counselors to sponsor programs on alternative careers and obstacles women face there. Counseling services should be encouraged to offer self-esteem of 
mutual support workshops to graduate women eager to stay in academia but uncertain -in spite of superior record - of their right to be there.

\section{Programs For Faculty Women}

During the 1970s there was an increase in the proportion of assistant professor positions that went to women (although no increase in the absolute number of women thus employed). ${ }^{10}$ These women are now in the pipeline: the 1980 s will see whether the y survive and move into the ranks of associate professor. Already there is some fear that they are not surviving, that the open door has become a revolving door. ${ }^{11}$ Faculty development can play an especially significant role assisting these women to tenure.

Obviously, that role will be secondary to the part played by departments and the institution as a whole but many of the programs that have been outlined for graduate women could, with modification, be usefully extended to faculty women. Certainly they may be as eager to share with each other, as with their same sex students, strategies for reconciling the personal and professional, meeting mentoring demands, carrying on feminist research, and dealing with male colleagues. Some activities, however, should be specifically designed for them:

(1) Meetings for those teaching in women and minority studies in which solutions to common problems are stressed. Besides the changes in teaching approach mentioned earlier, teachers of women and minority studies share other concerns-a sense of marginality, a vulnerable place in the curriculum, a lack of colleagues, isolation in their own department. By meeting together, not only can such faculty share solutions but they are more likely to evolve coalitions that can influence the institution overall.

(2) Workshops on the institution's tenure and promotion criteria. As in the case of the workshops for graduate students on the hiring process, these would be for both men and women but would benefit women more by opening up the process to scrutiny and discussion. In various studies, women scholars have identified the lack of objective criteria in the promotion and tenure process as the chief obstacle to 
their success. ${ }^{12}$ The opportunity to discuss this process might not only ease some women's suspicions but encourage the development of more objective criteria.

(3)Assignment of new faculty mentors. ${ }^{13}$ Once again, these assignments could be made for both and men and women but would be especially helpful to the young woman whose department has no one else of her sex or field of interest. Mentors can be of the same or different gender or department but should understand the institution well and be able to give frank advice on committee assignments, research efforts, teaching problems, or departmental politics.

Finally, there are several efforts that would benefit both graduate and faculty women. Although some might seem of a largely cosmetic nature, they are important and necessary reminders to any institution that even in 1982 "colleges are "bastions' of sex bias"14:

(1) Devote an issue of your faculty development newsletter to women in higher education, or to the situation of women on your campus, or to experience in teaching Women's Studies.

(2) Sponsor regional or all-campus panels and conferences on the issues just named.

(3) Develop a section of your faculty development library into one on women in higher education.

(4) Make certain that in general your public functions include women speakers in a proportion that matches, if it does not exceed, their representation on campus.

(5) Offer child care during all day or weekend activities.

\section{Conclusion}

There are, of course, some caveats. By focusing attention on women, I don't want to imply that they are more deserving than men, nor more troubled, nor more in need of help. I want to imply that for several reasons-biological, social, historical-the issues that confront them are in some measure different from those that affect men and thus demand a different response from faculty development.

Neither by focusing on women do I mean to imply all women faculty members want or favor the programs that I have described any more that all male faculty members have responded to development 
activities. As Jessie Bernard has written, "The population of academic women is itself no more homogeneous than is the total population of academia." "Queen bees," women who made it before the days of affirmative action or "raised consciousness" and feel other women can do it too if they are just good enough, certainly exist. There are also women, of course, who will perceive faculty development as hopelessly incapable of the profound transformation they envision not only for academia but for all of our society. With their sights on the long run, they would spurn such amelioration of the present situation as I think faculty development can achieve in the short run.

Even conceding these caveats, however, faculty development must accept the obligations of its vision for higher education and seek to make women as fully a part of academia as it has sought to make itself.

\section{References}

${ }^{1}$ In selecting women for emphasis, I am not disagreeing with David O. Justice who spoke of a new role for faculty development in the 1980 s in the recruitment, promotion, and assistance to tenure of not only women but of minority group faculty members. I concentrate on women only because my own experience at Stanford has been largely with them and has only recently begun with minority faculty. David $O$. Justice, The Future of Faculty Development, POD Quarterly 1 (1979), 40.

${ }^{2}$ Bernice Resnick Sandler, You've come a long way, maybe-or why it still hurts to be a woman in labor, Current Issues In Higher Education (1979), 13.

${ }^{3}$ Jessie Bernard, Academic Women, New York: New American Library, 1964, 114-125.

${ }^{4}$ Helen S. Asin, Career Profiles of Women Doctorates, in Academic Women on the Move,ed. by Alice Rossi and Alice Calderwood, New York: Russell Sage Foundation, 1973, 150; J. Gappa and B. Uehling. Women in Academe: Steps to Greater Equality. Research Report 1. Washington, D.C.: American Association for Higher Education, 1989, 67-68.

${ }^{5}$ See, for example, Barbara A. White, Up From the Podium: Feminist Revolution in the Classroom, Female Studies 4 (1971), 28-34 or Florence Howe and Carol Ahlum, Women's Studies and Social Change, in Rossi and Calderwood (1973), 393-423.

${ }^{6}$ Sandler (1979), 11.

${ }^{7}$ For an interesting critique of the latter theory see Georgis Sassen, Success Anxiety in Women: A Constructivist Interpretation of its Source and its Significance, Harvard Educational Review 50 (1980), 13- 24.

${ }^{8}$ For an example of a different pattern, see Sophie Freud Loewenstein, The Passion and Challenge of Teaching, Harvard Educational Review 50 (1980), 1-12. 
${ }^{9}$ For more information, write Marilla D. Svinicki at the Center for Teaching Effectiveness, University of Texas at Austin.

${ }^{10}$ Mary L. Spencer and Eva F. Bradford, Status and Needs of Women Scholars, in Handbook for Women Scholars: Strategies for Success, ed. by Monika Kehoe, U.S. Department of Education, 1980, 4.

${ }^{11}$ Ibid, 5.

${ }^{12}$ Ibid, 27. Margaret L. Rumbarger, Internal Remedies for Sex Discrimination in Colleges and Universities, Rossi and Calderwood (1973), 426-427.

${ }^{13}$ For a description of such a program for women, see Barbara Lazarus and Martha Tolpin, Engaging Junior Faculty in Career Planning: Altemative to the Exit Interview, Current Issues In Higher Education 2 (1979), 29-20.

${ }^{14}$ Higher Education Daily, 8 (October 21, 1980).

${ }^{15}$ Bernard (1964), 96. 